\title{
An Empirical Study on the Influential Factors of the Allocation Efficiency of Financial Resources in the Western Region
}

\author{
Hongjian $\mathrm{Li}^{1, \mathrm{a}^{*}}$ and Chi Fan ${ }^{2, \mathrm{~b}}$ \\ ${ }^{1}$ Lanzhou University of Technology School of Economics and Management, Gansu, China \\ ${ }^{2}$ Lanzhou University of Technology School of Economics and Management, Gansu, China \\ a914435055@qq.com, b1260752614@ qq.com
}

\section{Keywords: Western region; Financial resources; Allocation efficiency}

\begin{abstract}
This paper selects the data of twelve provinces and cities in the western region of China from 2011 to 2015, constructs the panel data and establishes the econometric model. It mainly analyzes the efficiency of allocating financial resources in the western region from three aspects: the marketization process, the degree of opening to the outside world and the Internet finance Influential factors for empirical research. The result shows that the acceleration of marketization and the development of Internet finance can promote the allocation efficiency of financial resources in the western region. The lack of opening up leads to the inefficient allocation of financial resources. It is proposed that the western region should optimize the credit structure, play the role of the insurance industry, make full use of foreign investment and emphasis on internet finance.
\end{abstract}

\section{Introduction}

Resources are scarce, so the rational allocation of resources is an indispensable part of regional economic development. The core of resource allocation is the allocation of financial resources to guide the allocation of other resources. At the same time, with the help of China's supply-side reform policy, if the financial resources can be rationally allocated, the pace of economic structural adjustment will also be accelerated, so as to promote economic growth. The western part of our country belongs to the underdeveloped areas. After years of hard work, the economy has been developing continuously and financial services have been gradually improving. However, compared with provinces and cities in other regions, the overall economic situation is still at a relatively backward stage. The inefficiency of the allocation of financial resources is the main reason leading to this situation. Based on the analysis of the influential factors of the allocation efficiency of financial resources in the western region, this paper puts forward the feasible suggestions.

\section{Related Literature and Theoretical Review}

The Connotation of Financial Resources Allocation and Efficiency. Goldsmith (1969) pointed out that financial resources can be seen as the financial structure, which is composed of financial instruments, financial markets and financial institutions and the relationship between the three [1]. Bai Qinxian (2000) believes that financial resources are divided into the following three levels: basic core financial resources, physical intermediate financial resources and overall functional high-level financial resources [2]. Wurgler (2000) uses the efficiency of capital allocation to measure a country's financial development [3]. Wang (2000) pointed out that when the allocation of financial resources reaches Pareto optimal, the allocation efficiency is the best [4].

The way of financial resources allocation. Panjing $\mathrm{Ru}$ (2016) that there are three modes of financial resources allocation: planning allocation model, market allocation model and mixed mode[5]. Liu Yue, Zheng Yuhang and Liao Gaoke (2017) pointed out that the allocation of financial resources can be divided into "quantity" and "price" two. The quantitative configuration includes the indirect configuration mainly based on the credit scale of commercial banks and the direct configuration based on capital markets. Price-based configuration mainly refers to the adjustment of interest rates and exchange rates affect the price of funds, thus optimizing the 
allocation of financial resources [6].

Factors Influencing the Allocation Efficiency of Financial Resources. Zeng Kanglin (2005) that in addition to bank loans, the securities market will affect the efficiency of financial resources allocation [7]. Jin Xuejun and Wang Yongjian (2011) analyzed the influencing factors of China's capital allocation efficiency and found that the level of financial development, the degree of opening to the outside world, the government intervention, the marketization process and the infrastructures all affect it [8]. Li Shujin and Ying Qiu Xiao (2014) found through research that P2P financing has a positive relationship with the efficiency of China's financial resources allocation [9]. Liu Yue and Liao Gaoke (2017) pointed out that by adjusting the credit, stock and bond market size can improve the efficiency of financial resources allocation [6].

As can be seen from the above literature, financial resources include financial institutions, financial instruments and financial markets. In this paper, the efficiency of financial resource allocation is defined as the degree to which financial resources use the price mechanism to flow from areas with low returns to areas with high returns.

\section{Data Index Selection and Model Establishment}

Sample Selection and Data Source. According to the policy of western development, the western region includes 12 provinces and cities in Sichuan, Guizhou, Yunnan, Tibet, Shaanxi, Gansu, Qinghai, Ningxia, Xinjiang, Guangxi and Chongqing. The study sample is the above 12 provinces and cities, and the selected time period is from 2011 to 2015. Based on the above indexes, the influencing factors of the allocation efficiency of financial resources in various provinces and cities in the western region are systematically studied. Data sources are wind database and 2011-2015 Statistical Communique on National Economic and Social Development of 12 provinces and municipalities in west China.

To Make Assumptions. The main influencing factors of the efficiency of financial resources allocation are the process of marketization, the degree of opening to the outside world and the development of Internet finance. In addition, the number of employees also affects them. The process of marketization is embodied in the scale of bank credit, the size of the securities market and the scale of insurance. The securities market mainly refers to the stock market and the bond market. The internet has a wide range of financials, represented by a typical P2P financing model. The western part of our country belongs to the underdeveloped areas. The economy is relatively backward with a low degree of marketization. Capital allocation mainly involves bank credit. Thus, two hypotheses in this paper are proposed:

Hypothesis 1: The acceleration of marketization has a positive relationship with the efficiency of allocating financial resources in the western region.

Hypothesis 2: The development of internet finance has a positive relationship with the efficiency of financial resources allocation in the western region.

\section{Selection of Indicators.}

Table 1 Variable analysis

\begin{tabular}{|c|c|}
\hline Explained variable & Financial added value \\
\hline \multirow{4}{*}{ Explanatory variables } & Loan balance \\
\cline { 2 - 2 } & Stock raising amount \\
\cline { 2 - 2 } & Bond financing amount \\
\cline { 2 - 2 } & Premium income \\
\cline { 2 - 2 } & Foreign investment \\
\cline { 2 - 2 } & Number of employees in financial institutions \\
\cline { 2 - 2 } & P2P funding \\
\hline
\end{tabular}




\section{Empirical Results Analysis}

According to the research of domestic and foreign scholars and the above analysis, a multiple linear regression model can be established:

$$
\ln Y=C+\beta 1 \ln X 1+\beta 2 \ln X 2+\beta 3 \ln X 3+\beta 4 \ln X 4+\beta 5 \ln X 5+\beta 6 \ln X 6+\beta 7 \ln X 7
$$

Where $\mathrm{Y}$ is the financial added value of each region, $\mathrm{X} 1$ is the loan balance, $\mathrm{X} 2$ is the amount of stock financing, $\mathrm{X} 3$ is the amount of bond financing, $\mathrm{X} 4$ is the premium income, $\mathrm{X} 5$ is the amount of foreign investment, $\mathrm{X} 6$ is the number of financial institutions, $\mathrm{X} 7$ is the amount of $\mathrm{P} 2 \mathrm{P}$ financing.

Table 2 Panel data regression analysis results

\begin{tabular}{ccccc}
\hline \multicolumn{1}{c}{ Variable } & Coefficient & Std. Error & t-Statistic & Prob.* \\
\hline X1 & 0.933367 & 0.130676 & 7.142577 & 0.0000 \\
C & 4.116872 & 1.491951 & 2.759388 & 0.0078 \\
X4 & 0.916213 & 0.178613 & 5.129606 & 0.0000 \\
X5 & -2.576533 & 0.566535 & -4.547877 & 0.0000 \\
X7 & 0.310710 & 0.095854 & -3.241503 & 0.0020 \\
\hline \hline R-squared & 0.970422 & Mean dependent var & 5.886283 \\
Adjusted R-squared & 0.968270 & S.D. dependent var & 1.023372 \\
S.E. of regression & 0.182291 & Akaike info criterion & -0.486768 \\
Sum squared resid & 1.827653 & Schwarz criterion & -0.312239 \\
Log likelihood & 19.60304 & Hannan-Quinn criter. & -0.418500 \\
F-statistic & 451.1166 & Durbin-Watson stat & 2.107570 \\
Prob(F-statistic) & 0.000000 & & & \\
\hline \hline
\end{tabular}

The regression results are established by Eviews8.0 software multiple linear regression model, using stepwise regression method. As can be seen from Table 2, of the seven explanatory variables, variables $\mathrm{X} 1, \mathrm{X} 4, \mathrm{X} 5$ and $\mathrm{X} 7$ are significant at the 5\% statistical level, while variables $\mathrm{X} 2, \mathrm{X} 3$ and $\mathrm{X} 6$ fail the test. To a certain extent, this shows that the development of the stock market in the western region of our country is not yet mature and the financing ability is relatively weak, and it is temporarily unable to exert a significant influence on the efficiency of the allocation of financial resources. The number of practitioners in financial institutions also has no obvious effect on the efficiency of financial resources allocation. The coefficients of variables $\mathrm{X} 1, \mathrm{X} 4$ and $\mathrm{X} 7$ are all positive, and the efficiency of financial resource allocation is in a positive relationship with the marketization process and the development of the Internet. While the coefficient of X5 is negative, the efficiency of financial resource allocation is negatively related to the degree of opening to the outside world. In theory, the degree of opening to the outside world should be positively related to the efficiency of financial resources allocation, but the results obtained in this paper are slightly different from those of the theory. According to the actual situation, it may be that the opening up to the outside world in western provinces and cities is not adequate and there is no adequate and reasonable use of foreign investment, which leads to the fact that it is contrary to the theory.

\section{Conclusion Analysis and Policy Suggestions}

Conclusion Analysis. In this paper, Eviews8.0 software to build multiple linear regression model to study the impact of financial resources allocation efficiency factors and found that the acceleration of the market process and the development of Internet finance and financial resources in western regions is a direct relationship between the efficiency of the allocation of resources, and the lack of opening up led to The inefficient allocation of financial resources. So assuming a set up, assuming two established. 
Policy Recommendations. Emphasis on capital markets. Capital markets include not only the stock market, but also the bond market. In addition to the role of the stock market financing, but also to help enterprises carry out institutional reform and other publicity, you can expand the direct financing channels for enterprises to increase investment in capital. The enterprise through the stock market reform of the system, investors can be integrated into the different economic sectors to participate in the subscription of shares, so that the diversification of ownership development.

Make full use of foreign investment.In attracting foreign investment, policy orientation plays an indispensable role. On the one hand, the favorable preferential tax policies for the development of the western region, after introducing foreign capital, can make a more comprehensive construction of infrastructure and optimize the objective environment for external investment so as to increase the amount of foreign investment. On the other hand, the major course required to effectively guide external investment needs to take into account the high-tech industries while diverting external investment to manufacturing.

Emphasis on Internet finance.The emergence of Internet finance has a great impact on the traditional financial industry, the biggest advantage is that it reduces transaction costs. Financial institutions can use the Internet to carry out related services, so that financial resources can be quickly delivered to users, reducing many intermediate links and greatly improving the efficiency of financial resource allocation.

\section{References}

[1] Goldsmith: R.Financial Structure and Development (Yale University Press, United States 1969) .

[2] Q.X. Bai: International Finance, Vol. 2 (2000), No.2, p.7-14.

[3] Wurgler J: Journal of Financial Economics, Vol. 13 (2000), No.4, p.58.

[4] Z.S.Wang:Finance and Trade Economics, Vol. 5 (2000), No.4, p.19-22.

[5] J.R.Pan:Gansu Province, the Allocation of Financial Resources Efficiency(MS.,Lanzhou Jiaotong University, China 2016),p.12.

[6] Y.Liu:Statistics and Decision, Vol. 4(2017) No. 4, p.167-169.

[7] K.L.Zeng:Financial Research, Vol. 13(2005) No. 4, p. 23.

[8] X.J.Jin and Y.J.Wang:Shanghai Finance, Vol. 16( 2011)No. 8, p.23-27.

[9] S.J.Li and Q.X.Yi: Business Globalization, Vol. 13( 2014) No.3, p.45-51. 